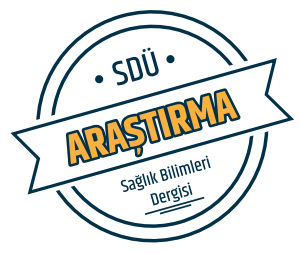

\title{
Diş Hekimlerinin Çalışma Şartlarının Mesleki Kas-İskelet Sistemi Hastalıklarına Etkisi
}

\section{Effect of Dentist Working Conditions on Occupational Musculoskeletal System Diseases}

\author{
Meral Soylu', Selma Altındiş² \\ ${ }^{1}$ Bilecik Ağız ve Diş Sağlığı Merkezi, Bilecik, Türkiye. \\ 22Sakarya Üniversitesi İşletme Fakültesi, Sağlık Yönetimi Bölümü, Sakarya, Türkiye.
}

\section{Özet}

Amaç: Diş hekimliği mesleği, uzun süre aynı pozisyonda çalışma zorunluluğu olan ve uygunsuz biçimlerde kas-iskelet sisteminin kullanılmasına bağlı olarak gelişen bazı meslek hastalıkları riskiyle karşı karşıyadır. Bu meslek hastalıkları içinde mekanik ağrı, alerji, enfeksiyon, dermatit gibi bazı sağlık sorunları sıklıkla görülmektedir. Bu çalışmada Sakarya, Bilecik Merkez ve Bozüyük Ağız ve Diş Sağlığı Merkezlerinde çalışan diş hekimlerinde kas-iskelet sistemi şikayetleri ve etkileyen faktörlerin belirlenmesi amaçlanmıştır.

Materyal-Metot: Tanımlayıcı tipte bir çalışmadır. Veriler, Genişletilmiş Nordic Kas İskelet Anketi aracilığg ile araştırmacılar tarafından Nisan 2017-Mayıs 2017 tarihleri arasında 83 diş hekiminden toplanmıştır.

Bulgular: Katılımcıların \%50,6'sı erkektir. Araştırmaya katılanların yaş ortalaması 37,81 $\pm 8,23$ yıldır. Anketi cevaplayan diş hekimlerinin kas-iskelet sistemi yakınma sıklıklarının son 12 ayda \%79,5 olduğu, son bir ay içinde $\% 69,9$ ve anketin yapıldığı gün \% 48,2 olduğu saptanmıştır. Diş hekimlerinden son 12 ayda kas-iskelet sistemi yakınmasına sahip olanların en fazla boyun bölgesinde $(\% 78,3)$ yakınması olduğu, daha sonra sirasiyla bel bölgesinde $(\% 56,6)$ ve sirt bölgesinde $(\% 55,4)$ yakınmalarının olduğu belirlenmiştir. Son bir ayda kas-iskelet sistemi yakınma sıklığı, çalışma süresi 15 yildan fazla olanlarda $(p=0,019)$, kadinlarda $(p=0,001)$, sürekli eğilerek çalışanlarda $(p=0,013)$ daha fazladır. Çalışma ortamını riskli bulanların yakınılan bölge sayısı riskli bulamayanlara göre yaklaşık iki kat fazladır.

Sonuç: Diş hekimlerinin mesleki riskleri azaltacak davranış değişikliğini sağlamak üzere yapılan iş, çalışma pozisyonu, çalışma şartları, yaşam tarzı ve alışkanlıklar gibi konularda hizmet içi eğitimlerinin düzenlenmesinin faydalı olacağı düşünülmektedir.

Anahtar kelimeler: Diş hekimleri, mesleki hastalıklar, kasiskelet sistemi.

\begin{abstract}
Objective: The profession of dentistry that has the obligation to work in the same position for is at risk of some occupational diseases which develops due to the use of musculoskeletal system in inappropriate forms. Some health problems such as mechanical pain, allergy, infection, dermatitis are frequently seen in these occupational diseases. In present study the musculoskeletal system problems of dentists working in Oral and Dental Health Centers in Sakarya, Bilecik, Bozüyük and factors affecting these complaints were investigated.
\end{abstract}

Material-Method: This was a descriptive type of study. The data was collected of 83 dentist, by the investigator between April 2017-May 2017 with Extended Nordic Musculoskeletal Questionnaire.

Results: Involved in study $50.6 \%$ were male. Mean age of participants was $37,81 \pm 8,23$ years. Musculoskeletal system complaints among the dentists participated in the study were $\% 79,5 \%$ in last 12 months, $\% 69,9 \%$ in last month and $\% 48,2 \%$ in the day of questionnaire. In the last 12 months the prevalence of musculoskeletal system complaints were most frequently seen at neck region $(78.3 \%)$, low back region $(56.6 \%)$ and upper back region $(55,4 \%)$ respectively. The frequency of musculoskeletal system problems in the last month was higher among females $(\mathrm{p}=0.001)$, working time is over 15 years $(p=0,019)$, working in bending position constantly $(\mathrm{p}=0,013)$.

Conclusions: Those who evaluate the working environment as risky complain about painful areas twice higher than those who do not evaluate the working environment as risky. It is thought that arrangement of in service training to establish occupational risk and behavioral changes against job work, working position and life style of dentists will be useful.

Keywords: Dentist, occupational diseases, musculoskeletal system.

\section{Giriş}

Çalışanların sağlığı ile çalışma ortamları arasında birbirini etkileyen karşılıklı bir etkileşim vardır. Sağlık, bireylerin çalışma yaşamlarını, çalışma yaşamı da bireylerin sağlıklarını etkiler (1). Dünya Sağlık Örgütü tarafından “yalnızca hastalık ya da sakatlığın bulunmaması değil, aynı zamanda bedenen, ruhen ve sosyal yönlerden de tam bir iyilik durumudur" şeklinde yapılan sağlık tanımında "sosyal" kavramı ile bireyin önce bir iş sahibi olması, daha sonra da sağlıklı bir çalışma ortamında bireyin işine uyum göstererek çalışması vurgulanmaktadir (2).

Çalışma yaşamında sıklıkla görülen önemli sorunlardan biri 
de kas-iskelet sistemi ağrılarıdır (3). Aslında kas-iskelet sistemi ağrıları, günümüz modern toplumlarının temel sorunları olarak görülmektedir (4). Bu sorun fiziksel, sosyal, kültürel ve kişisel risk faktörlerini kapsar (5). Fiziksel risk faktörleri olarak kabul edeceğimiz sıklıkla eğilme, itme ve çekme hareketleri, durağan çalışma pozisyonu, ağırlık kaldırma, tekrarlayan hareketler, vibrasyon, uzun süreli, ağır ve yoğun çalışma gibi faktörler kas-iskelet sistemi ağrıları ile sonuçlanabilmektedir (6).

Diş hekimliği mesleği, gerek bedenen gerekse de zihinsel olarak çok hassas çalışılması gereken bir meslektir. Eğer buna uygunsuz çalışma şartları ve artan iş yükü de ilave olursa bu meslek çok yorucu ve yıpratıcı olabilir. Bu durumda diş hekimlerinde bazı sağılık problemlerinin ortaya çıkması gayet doğaldır. Ayrıca diş hekimliği mesleği, uzun süre aynı pozisyonda çalışma zorunluluğu olan ve uygunsuz biçimlerde kas-iskelet sisteminin kullanılmasına bağlı olarak gelişen bazı meslek hastalıkları riskiyle karşı karşıyadır.

Diş hekimliği mesleğindeki en olumsuz durumun zamanla ortaya çıkan sağlık problemleri olduğu bildirilmektedir (7). Diş hekimlerinin farkında olması gereken bazı mesleki risk faktörleri vardır. Bunlar: Diş hekimlerinin göz, kulak, el ve parmaklarını etkileyen faktörler, kan ve hava yolu ile bulaşma riski olan hastalıklar, dermatit, egzama gibi alerjik reaksiyonlar, kas ve iskelet sistemi bozuklukları, civa vb materyaller ile gelişebilen toksisite, çok yoğun ve ağır iş koşullarından kaynaklı stres bu risklerdendir. O halde diş hekimleri bu risk faktörlerinin farkında olmalı, bunun için gerekli koruyucu önemleri sorunlar otaya çıkmadan önce almalıdır. Eğer meslekle ilgili risk faktörleri diş hekimleri tarafından doğru anlaşılır ve gerekli önlemler alınırsa diş hekimliği güvenli bir meslek olarak görülmektedir (8).

Diş hekimliği uygulamaları, temas sakatlanmaları yerine, kümülatif mikrotravma ve uygunsuz çalışma pozisyonları nedeniyle kas dengesizlikleri, nöromüsküler sınırlanmalar, ağrı ve fonksiyon bozukluğu gibi hasarlara yol açmaktadır (9). Diş hekimlerinin en iyi çalışma pozisyonlarında dahi, yer çekiminin karşısında sabit bir pozisyonda bedenlerinin hareketsiz kalabilmesi için \%50'den fazla vücut kasının kasılması gerektiği belirtilmektedir. Bu duruşların çoğunlukla diş hekimlerinde klasik kas dengesizlikleriyle karakterize uzun süren, tekrarlayıcı kas kasılmalarına neden olmaktadır (10).

Bu çalışma; Sakarya, Bilecik Merkez ve Bozüyük Ağız ve Diş Sağlığı Merkezlerinde çalışan diş hekimlerinin çalışma koşulları ve mesleki özelliklerine bağlı olarak gelişen kasiskelet sistemi sorunlarını araştırmak amacıyla yapılmıştır.

\section{Materyal-Method}

Araştırma, tanımlayıcı tipte bir çalışma olup, veri toplama aracı olarak katılımcılara sosyo-demografik özelliklerine, çalışma hayatına ve kas-iskelet sistemi yakınmalarına ilişkin soruları içeren anket kullanılmıştır. Çalışma evrenini Sakarya ve Bilecik ilinde hizmet veren kamuya ait Sakarya, Bilecik Merkez ve Bozüyük Ağız ve Diş Sağlığı hastanelerinde Nisan 2017-Mayıs 2017 tarihleri arasında çalışan 85 Diş
Hekimi oluşturmaktadır. Araștırmada evrenin tamamına ulaşılmak hedeflenmiş ve anketi cevaplamayı kabul eden 83 Diş Hekimine anket uygulanmıştır.

Ankette birinci bölümünde demografik ve mesleki özelliklerini belirleyen bağımsız değişken olarak; cinsiyet, yaş, vücut ağırlığı, boy uzunluğu, VKİ (Vücut Kitle İndeksi), medeni durum, evde beraber yaşayan yedi yaş altı çocuk olma durumu, sigara içme durumu, düzenli olarak egzersiz/ spor yapma durumu, gebe kalma ve doğum yapma konusu, kronik bir hastalığı olma durumu, hekim tarafından tanı konmuş kas-iskelet sistemi hastalığı olma hali, mezun olunan fakülte varsa doktora eğitimi, diş hekimi olarak meslekte çalışma yılı, günlük çalışma süresi, ek iş yapma durumu, günlük bakılan hasta sayısı, bakılan hasta grubu, günlük yapılan işlemlerin sayısı, işyeri çalışma ortamını değerlendirmeleri, çalışırken oturulan koltuğunda bel desteği varlığı, günlük bilgisayar kullanma süresi, çalışma pozisyonu ile ilgili eğitim alma durumu, çalışma pozisyonu, kas-iskelet sistemi yakınmalarının sıklığı, şiddeti, tatil günlerinde azalıp azalmadığı sorulmuştur.

Kişinin beyanına dayalı kas-iskelet sistemi semptomlarının yaygınlığını değerlendirmek için Genişletilmiş Nordic Kas İskelet Anketi (Extended Nordic Musculosceletal Questionnare NMQ-E) uygulanmıştır. İlk defa 1987 yılında Kuorinka ve arkadaşları tarafından geliştirilmiş olan bu anket (Nordic Musculoskeletal Questionnaire (NMQ) daha sonra Dawson ve arkadaşları tarafından geliştirilerek Genişletilmiş Nordic Kas İskelet Anketi (Extended version of the Nordic Musculoskeletal Questionnaire (NMQ-E) halini almıştır. Ülkemizde ise, Doğan tarafından 2011 yılında Ankara İli Ağız Diş Sağlığı Merkezlerinde de çalışan diş hekimlerine uygulanmıştır (11).

NMQ-E ile dokuz vücut bölgesindeki (boyun, omuz, dirsek, el bileği/el, sırt, kalça/uyluk, diz ve ayak bileği/ayak) kasiskelet sistemine ilişkin yakınma olup olmaması durumu tespit edilmiştir. Ayrıca bağımlı değişkenlerimiz (boyun, omuz, dirsek, el bileği/el, sırt, kalça/uyluk, diz ve ayak bileği/ ayak bölgesi) ile diş hekimi olarak meslekte çalışma yıll, günlük çalışma süresi, ek iş yapma durumu, günlük bakılan hasta sayısı, bakılan hasta grubu, günlük yapılan işlemlerin sayısı, işyeri çalışma ortamını değerlendirmeleri, çalışırken oturulan koltuğunda bel desteği varlığı, günlük bilgisayar kullanma süresi, çalışma pozisyonu ile ilgili eğitim alma durumu, çalışma pozisyonları gibi demografik özellikler arasındaki ilişkileri incelenmiştir.

Çalışmada verilerin analizi SPSS 24.0 ile yapılmış ve sonuçları \%95 güven düzeyinde değerlendirilmiştir. Analizler kapsamında sürekli değişkenlerin normal dağılıma uygunluğunun belirlenmesi için basıklık ve çarpıklık katsayıları incelenmiştir. Basıklık ve çarpıklık değerlerinin +3 ile -3 arasında olması normal dağılım için yeterli görülmektedir (12-15). Buna göre değişkenlerin normal dağılıma uygun olduğu belirlenmiş ve analizlerde parametrik test teknikleri kullanılmıştır. Sürekli değişkenlerin karşılaştırılmasında t testi ve ANOVA testi kullanılmıştır. Bununla birlikte çalışmada kategorik değişkenler arasındaki 
Tablo 1. Vücuttaki ağrı duyulan bölge sayısının bazı mesleki özelliklere göre t-testi ve anova sonuçları.

\begin{tabular}{|c|c|c|c|c|c|c|c|c|c|c|c|c|c|}
\hline & & \multicolumn{3}{|c|}{$\begin{array}{c}\text { Kaç bölgede ağrı } \\
\text { var? }\end{array}$} & \multicolumn{3}{|c|}{$\begin{array}{c}\text { Son } 12 \text { ay süresince } \\
\text { herhangi bir } \\
\text { zamanda } \\
\text { vücudunuzun kaç } \\
\text { bölgesinde sorun } \\
\text { oldu? }\end{array}$} & \multicolumn{3}{|c|}{$\begin{array}{c}\text { Son bir ay (4 hafta) } \\
\text { süresince herhangi } \\
\text { bir zamanda } \\
\text { vücudunuzun kaç } \\
\text { bölgesinde sorun } \\
\text { oldu? }\end{array}$} & \multicolumn{3}{|c|}{$\begin{array}{c}\text { Bugün vücudunuzun } \\
\text { kaç bölgesinde } \\
\text { sorun oldu? }\end{array}$} \\
\hline & & Ort. & ss & $\underset{\text { leğeri }}{\text { p }}$ & Ort. & ss & $\underset{\text { dě̆geri }}{\text { p }}$ & Ort. & ss & $\underset{\text { leøgeri }}{\text { P }}$ & Ort. & ss & $\underset{\text { děğeri }}{\text { p }}$ \\
\hline \multirow{2}{*}{$\begin{array}{l}\text { Kronik hastalığınız } \\
\text { var mı? }\end{array}$} & Evet & 3,00 & 1,33 & \multirow{2}{*}{0,426} & 2,00 & 1,49 & \multirow{2}{*}{0,245} & 1,40 & 1,65 & \multirow{2}{*}{0,187} & 0,70 & 0,82 & \multirow{2}{*}{0,076} \\
\hline & Hayır & 3,59 & 2,27 & & 2,95 & 2,48 & & 2,42 & 2,35 & & 1,34 & 1,97 & \\
\hline \multirow{4}{*}{ Çalışma süresi } & 5 yil ve daha az & 2,25 & 1,82 & \multirow{4}{*}{0,128} & 1,50 & 1,57 & \multirow{4}{*}{0,129} & 0,83 & 1,27 & \multirow{4}{*}{0,055} & 0,58 & 1,00 & \multirow{4}{*}{0,391} \\
\hline & $6-10 \mathrm{y} 11$ & 3,41 & 2,46 & & 2,59 & 2,67 & & 2,09 & 2,51 & & 1,05 & 1,91 & \\
\hline & $11-15$ y1l & 3,73 & 2,03 & & 3,14 & 2,55 & & 3,00 & 2,41 & & 1,41 & 2,24 & \\
\hline & $\begin{array}{l}16 \text { y1l ve daha } \\
\text { fazla }\end{array}$ & 4,00 & 2,08 & & 3,37 & 2,20 & & 2,56 & 2,15 & & 1,63 & 1,80 & \\
\hline \multirow{2}{*}{ Bakılan hasta grubu } & $\begin{array}{l}\text { Genellikle erişkin } \\
\text { hasta }\end{array}$ & 4,31 & 2,33 & \multirow{2}{*}{0,105} & 3,81 & 2,54 & \multirow{2}{*}{0,068} & 3,06 & 2,91 & \multirow{2}{*}{0,141} & 2,00 & 1,90 & \multirow{2}{*}{0,081} \\
\hline & $\begin{array}{l}\text { Hem çocuk hem } \\
\text { erișkin hasta }\end{array}$ & 3,33 & 2,11 & & 2,60 & 2,32 & & 2,12 & 2,11 & & 1,09 & 1,84 & \\
\hline \multirow{2}{*}{$\begin{array}{l}\text { Çalışmama ortamı } \\
\text { olumsuz yönde } \\
\text { etkileyen sorun var } \\
\text { mı? }\end{array}$} & Evet & 3,86 & 2,27 & \multirow[b]{2}{*}{0,078} & 3,20 & 2,50 & \multirow[b]{2}{*}{0,085} & 2,52 & 2,35 & \multirow[b]{2}{*}{$\mathbf{0 , 2 8 8}$} & 1,44 & 2,08 & \multirow[b]{2}{*}{0,298} \\
\hline & Hayır & 3,00 & 1,95 & & 2,27 & 2,15 & & 1,97 & 2,20 & & 1,00 & 1,50 & \\
\hline \multirow{3}{*}{$\begin{array}{l}\text { Çalışmama } \\
\text { ortamının riskini } \\
\text { dě̆grlendirin }\end{array}$} & Az riskli & 3,00 & 2,03 & \multirow{3}{*}{0,001} & 2,75 & 2,34 & \multirow{3}{*}{0,060} & 2,30 & 2,49 & \multirow{3}{*}{0,105} & 1,40 & 1,76 & \multirow{3}{*}{0,073} \\
\hline & Riskli & 3,05 & 1,70 & & 2,37 & 1,75 & & 1,88 & 1,65 & & 0,86 & 1,08 & \\
\hline & Çok riskli & 5,05 & 2,58 & & 3,90 & 3,31 & & 3,20 & 3,04 & & 2,00 & 2,92 & \\
\hline Çalışma koltuğu & Evet & 3,13 & 1,73 & & 2,39 & 1,98 & & 1,90 & 1,80 & & 0,95 & 1,42 & \\
\hline desteği var mı? & Hayır & 4,59 & 2,89 & & 4,05 & 3,03 & & 3,41 & 3,08 & & 2,14 & 2,62 & \\
\hline & Ara sira & 3,59 & 2,34 & & 3,37 & 2,55 & & 2,78 & 2,53 & & 1,56 & 2,20 & \\
\hline $\begin{array}{l}\text { şimizie oturarar } \\
\text { çalıșır mısını?? }\end{array}$ & Siklıkla/genellikle & 3,50 & 1,98 & 0,940 & 2,67 & 2,17 & 0,040 & 2,10 & 1,95 & 0,083 & 0,97 & 1,30 & 0,368 \\
\hline & Sürekli & 3,33 & 2,23 & & 1,42 & 1,88 & & 1,17 & 1,85 & & 1,00 & 1,86 & \\
\hline & Ara sira & 3,56 & 2,22 & & 2,50 & 2,36 & & 2,15 & 2,34 & & 1,32 & 2,07 & \\
\hline $\begin{array}{l}\text { Isinızile ayakta } \\
\text { calısır misını?? }\end{array}$ & Siklıkla/genellikle & 3,83 & 2,16 & $\mathbf{0 , 5 5 7}$ & 3,04 & 2,60 & $\mathbf{0 , 5 8 2}$ & 2,42 & 2,47 & $\mathbf{0 , 8 8 0}$ & 1,42 & 1,95 & 0,764 \\
\hline & Sürekli & 3,16 & 2,17 & & 3,08 & 2,29 & & 2,40 & 2,14 & & 1,04 & 1,54 & \\
\hline & Ara sira & 3,41 & 2,04 & & 2,59 & 2,48 & & 1,95 & 2,46 & & 1,55 & 2,36 & \\
\hline $\begin{array}{l}\text { Isinizde eğilerek } \\
\text { çalıșır mısınız? }\end{array}$ & S1klıkla/genellikle & 3,79 & 2,56 & 0,729 & 2,75 & 2,78 & 0,762 & 2,11 & 2,70 & 0,436 & 1,18 & 2,00 & 0,719 \\
\hline & Sürekli & 3,36 & 1,95 & & 3,06 & 2,01 & & 2,70 & 1,76 & & 1,15 & 1,37 & \\
\hline
\end{tabular}

ilişki ki kare testi ile analiz edilmiştir.

Araştırma için Sakarya Üniversitesi Etik Kurulundan etik kurul onayı ve Kamu Hastaneler Kurumu Bilecik ve Sakarya İli Kamu Hastaneler Birliği Genel Sekreterliğinden anket uygulama izni alınmıştır.

\section{Bulgular}

Çalışma kapsamına alınan 83 diş hekiminin demografik ve mesleki özelliklerine ilişkin verilerden genel bir değerlendirme yapılabilmesi için tanımlayıcı istatistiklerden biri olan frekans dağılımları kullanılmıştır.
Katılımcıların \%50,6'sı erkektir. Araştırmaya katılanların yaş ortalaması 37,81 $\pm 8,23$ yıldır. Çalışanların \%78,3'ünün boyun, \%56,6'sının bel, \%55,4'ünün sirt, \%51,8'inin omuz bölgesinde sorunu olduğu saptanmıştır. Katılımcıların \%1,5'i boyun, \%3'ü el bilek, \%6,4'ü bel, \%8,7'i diz ağrısı nedeniyle hastaneye yattığı; \%7,7'i boyun, \%16,7'i dirsek, \%15,2'i el bilek, \%8,5'i bel, \%20'i kalça, \%8,7'i diz ağrısından dolayı görevini (geçici de olsa) değiştirmek zorunda kaldığı belirlenmiştir.

Ayrıca katılımcıların \%74,5'inin boyun, \%69,7'sinin omuz, \%61,5'inin sırt, \%70,3'ünün bel bölgesinde oluşan sorun 
nedeniyle ilaç aldı̆̆ 1 ; \%18,2'sinin boyun, \%12,1'inin omuz, \%24,3'ünün bel, \%12,5'inin kalça bölgesi sorunu nedeniyle hastalık izni (rapor ya da izni) aldığı saptanmıştır. Çalışmaya katılan diş hekimlerinin \%84,6'sının boyun, \%88,4'ünün omuz, \%89,1'inin sirt, \%87,9'unun el bilek, \%89,4'ünün bel ağrısının tatil günlerinde azaldığı belirlenmiştir.

Vücuttaki ağrı duyulan bölge sayısının, bakılan hasta grubu, çalışma koltuğu desteği olup olmaması, işlerinde oturarak çalışma düzeyi, işlerinde ayakta çalışma düzeyi, işlerinde eğilerek çalışma düzeyi, gibi bazı mesleki özelliklere göre t-testi ve anova analizleri yapılmış ve sonuçları Tablo 1'de verilmiştir.

Analiz sonuçlarında çalışma ortamının risk durumunu değerlendiren gruplara göre ağrı olan bölge sayısı ortalamaları arasında istatiksel olarak anlamlı farklılık saptanmıştır $(\mathrm{p}=0,001)$ (Tablo 1). Çalışma ortamını çok riskli olarak değerlendiren grubun diğer gruplara göre ağriyan bölge ortalamasının yüksek olduğu belirlenmiştir.

Bu araştırmada, çalışma koltuğu desteği olanlar ile olmayanlar arasında ağrıyan bölge sayısı açısından istatistiksel olarak anlamlı bir farklılık bulunmuştur $(p=0,001)$. Çalışma koltuğu desteği olmayanların ağrılı olan bölge sayısının, olanlara göre daha yüksek olduğu belirlenmiştir. Çalışma koltuğu desteği olanlar ile olmayanlar arasında ise son 12 ay ve son bir ay içerisinde vücudunda birden fazla sorun olma durumu bakımından ise istatistiksel olarak anlamlı bir farklılık bulunmuştur ( $p=0,001)$. Başka bir deyişle, son 12 ay ve son bir ay içerisinde vücudunda birden fazla sorun olma durumu, çalışma koltuğu desteği olup olmasına göre anlamlı bir farklılık göstermektedir. Katılımcıların oturarak çalışma düzeylerine (arasıra, genellikle ve sürekli) göre son 12 ay içerisinde vücudunda birden fazla sorun olma durumu arasında da istatistiksel olarak anlamlı bir farklılık $\operatorname{saptanmıştır}(p=0,001)$. (Tablo1).

Boyun, omuz, sırt ve bel vücut bölgelerinde ağrı görülme durumunun, kronik hastalığı olup olmadığı, çalışma süresi, bakılan hasta grubu, çalışma koltuğu desteği olup olmaması, işlerinde oturarak çalışma düzeyi, işlerinde ayakta çalışma düzeyi, işlerinde eğilerek çalışma düzeyi gibi bazı meslek özellikler ile ilişkisini belirlemek üzere ki-kare analizi yapılmış ve sonuçları Tablo 2'de verilmiştir.

Yapılan analizlerin sonucu en fazla sorun olarak algılanan vücut bölgeleri sırası ile boyun, bel, sırt ve omuz bölgeleridir. Katılımcıların bu dört bölgede ağrı görülme durumunun meslek özellikleri ile ilişkisi Tablo 2'de incelenmiştir. Sürekli eğilerek çalışanlarda boyun bölgesinde sorunlarının daha fazla olduğu saptanmıştır. Boyun bölgesinde ağrı ile eğilerek çalışma arasında anlamlı bir ilişki olduğu görülmüştür $(\mathrm{p}=0,048)($ Tablo2).

Omuz bölgesinde sorun olma durumu ile meslekte geçirilen süre arasında istatistiksel açıdan anlamlı bir ilişki saptanmıştır(p=0,009) (Tablo2). Meslek hayatında çalışma süresi 10 yıldan fazla olan katılımciların omuz bölgesinden şikayet ve sorunlarının daha çok olduğu belirlenmiştir.

Çalışma ortamını çalışan sağlığı açısından sağlıksız ve riskli bulan katılımcıların omuz bölgesinde ağrı şikayetleri de daha fazla görülmektedir. Çalışmaya katılan diş hekimlerinin omuz bölgesinde ağrı sorunu ile çalışma ortamını çalışan sağlığı açısından sorunlu/riskli bulma arasında istatistiksel açıdan anlamlı bir ilişki vardır $(\mathrm{p}=0,012)$ (Tablo2). Sırt ağrısı ile ayakta çalışma ve çalışılan ortamı riskli değerlendirme arasında istatistiksel açıdan anlamlı bir ilişki $(p=0,035)$ (Tablo2). Sürekli ayakta çalışan, çalışılan ortamını çok riskli değerlendiren hekimlerde sırtta ağrı sorunları daha fazla olduğu belirlenmiştir.

Tablo 2. Boyun, omuz, sırt ve bel bölge ağrı görülme durumunun meslek özellikleri ile ilişkisi.

\begin{tabular}{|c|c|c|c|c|c|c|c|c|c|c|c|c|c|c|c|c|c|c|c|c|c|}
\hline & & \multicolumn{4}{|c|}{$\begin{array}{c}\text { Boyun bölgesinde } \\
\text { sorununuz oldu mu? }\end{array}$} & \multirow{3}{*}{ p değeri } & \multicolumn{4}{|c|}{$\begin{array}{l}\text { Omuz bölgesinden } \\
\text { sorununuz oldu mu? }\end{array}$} & \multirow{3}{*}{$\underset{\text { değeri }}{p}$} & \multicolumn{4}{|c|}{$\begin{array}{l}\text { Surt bölgesinde sorununuz } \\
\text { oldu mu? }\end{array}$} & \multirow{3}{*}{$\underset{\text { değeri }}{p}$} & \multicolumn{4}{|c|}{$\begin{array}{l}\text { Bel bölgesinden sorununuz } \\
\text { oldu mu? }\end{array}$} & \multirow{3}{*}{$\underset{\text { değeri }}{p}$} \\
\hline & & \multicolumn{2}{|c|}{ Evet } & \multicolumn{2}{|c|}{ Hayır } & & \multicolumn{2}{|c|}{ Evet } & \multicolumn{2}{|c|}{ Hayrr } & & \multicolumn{2}{|c|}{ Evet } & \multicolumn{2}{|c|}{ Hayır } & & \multicolumn{2}{|c|}{ Evet } & \multicolumn{2}{|c|}{ Hayır } & \\
\hline & & $\mathbf{n}$ & $\%$ & $\mathbf{n}$ & $\%$ & & $\mathbf{n}$ & $\%$ & $\mathbf{n}$ & $\%$ & & $\mathbf{n}$ & $\%$ & $\mathbf{n}$ & $\%$ & & $\mathbf{n}$ & $\%$ & $\mathbf{n}$ & $\%$ & \\
\hline \multirow{2}{*}{$\begin{array}{l}\text { Kronik hastalığmız } \\
\text { var mı? }\end{array}$} & Evet & 6 & $60,0 \%$ & 4 & $40,0 \%$ & \multirow{2}{*}{0,139} & 4 & $40,0 \%$ & 6 & $60,0 \%$ & \multirow[b]{2}{*}{0,4} & 4 & $40,0 \%$ & 6 & $60,0 \%$ & \multirow{2}{*}{0,297} & 6 & $60,0 \%$ & 4 & $40,0 \%$ & \multirow{2}{*}{0,818} \\
\hline & Hayr & 59 & $80,8 \%$ & 14 & $19,2 \%$ & & 39 & $53,4 \%$ & 34 & $46,6 \%$ & & 42 & $57,5 \%$ & 31 & $42,5 \%$ & & 41 & $56,2 \%$ & 32 & $43,8 \%$ & \\
\hline \multirow{4}{*}{ Çalıșma süresi } & 5 yil ve daha az & 7 & $58,3 \%$ & 5 & $41,7 \%$ & & 1 & $8,3 \%$ & 11 & $91,7 \%$ & \multirow{4}{*}{0,009} & 5 & $41,7 \%$ & 7 & $58,3 \%$ & \multirow{4}{*}{0,676} & 4 & $33,3 \%$ & 8 & $66,7 \%$ & \\
\hline & $6-10 \mathrm{yl}$ & 16 & $72,7 \%$ & 6 & $27,3 \%$ & Test & 11 & $50,0 \%$ & 11 & $50,0 \%$ & & 12 & $54,5 \%$ & 10 & $45,5 \%$ & & 10 & $45,5 \%$ & 12 & $54,5 \%$ & 0067 \\
\hline & $11-15 \mathrm{yl}$ & 18 & $81,8 \%$ & 4 & $18,2 \%$ & Yaplamaz & 14 & $63,6 \%$ & 8 & $36,4 \%$ & & 14 & $63,6 \%$ & 8 & $36,4 \%$ & & 13 & $59,1 \%$ & 9 & $40,9 \%$ & 0,067 \\
\hline & 16 yil ve daha fazla & 24 & $88,9 \%$ & 3 & $11,1 \%$ & & 17 & $63,0 \%$ & 10 & $37,0 \%$ & & 15 & $55,6 \%$ & 12 & $44,4 \%$ & & 20 & $74,1 \%$ & 7 & $25,9 \%$ & \\
\hline & Genellikle erişkin & 14 & $87,5 \%$ & 2 & $12,5 \%$ & & 12 & $75,0 \%$ & 4 & $25,0 \%$ & & 12 & $75,0 \%$ & 4 & $25,0 \%$ & & 10 & $62,5 \%$ & 6 & $37,5 \%$ & \\
\hline Bakulan hasta grubu & $\begin{array}{l}\text { Hem çocuk hem } \\
\text { erişkin hasta }\end{array}$ & 51 & $76,1 \%$ & 16 & $23,9 \%$ & 0,265 & 31 & $46,3 \%$ & 36 & $53,7 \%$ & 0,074 & 34 & $50,7 \%$ & 33 & $49,3 \%$ & 0,141 & 37 & $55,2 \%$ & 30 & $44,8 \%$ & 0,598 \\
\hline $\begin{array}{l}\text { Çalsssma ortammı } \\
\text { olumsuz yönde } \\
\text { etkileven sorun var }\end{array}$ & Evet & 42 & $84,0 \%$ & 8 & $16,0 \%$ & 0,202 & 32 & $64,0 \%$ & 18 & $36,0 \%$ & 0,012 & 32 & $64,0 \%$ & 18 & $36,0 \%$ & 0,087 & 32 & $64,0 \%$ & 18 & $36,0 \%$ & 0,149 \\
\hline $\mathrm{m}$ ? & Hayr & 23 & $69,7 \%$ & 10 & $30,3 \%$ & & 11 & $33,3 \%$ & 22 & $66,7 \%$ & & 14 & $42,4 \%$ & 19 & $57,6 \%$ & & 15 & $45,5 \%$ & 18 & $54,5 \%$ & \\
\hline & Az riskli & 14 & $70,0 \%$ & 6 & $30,0 \%$ & & 7 & $35,0 \%$ & 13 & $65,0 \%$ & & 9 & $45,0 \%$ & 11 & $55,0 \%$ & & 10 & $50,0 \%$ & 10 & $50,0 \%$ & \\
\hline ing & Riskli & 33 & $76,7 \%$ & 10 & $23,3 \%$ & & 21 & $48,8 \%$ & 22 & $51,2 \%$ & 0,035 & 20 & $46,5 \%$ & 23 & $53,5 \%$ & 0,009 & 22 & $51,2 \%$ & 21 & $48,8 \%$ & 0,163 \\
\hline & Çok riskli & 18 & $90,0 \%$ & 2 & $10,0 \%$ & & 15 & $75,0 \%$ & 5 & $25,0 \%$ & & 17 & $85,0 \%$ & 3 & $15,0 \%$ & & 15 & $75,0 \%$ & 5 & $25,0 \%$ & \\
\hline Çalıșma koltuğu & Evet & 47 & $77,0 \%$ & 14 & $23,0 \%$ & 0446 & 29 & $47,5 \%$ & 32 & $52,5 \%$ & $0 \geq 29$ & 30 & $49,2 \%$ & 31 & $50,8 \%$ & 0008 & 35 & $57,4 \%$ & 26 & $42,6 \%$ & 1000 \\
\hline desteği var $\mathrm{ml}$ ? & Hayr & 18 & $81,8 \%$ & 4 & $18,2 \%$ & 0,446 & 14 & $63,6 \%$ & 8 & $36,4 \%$ & 0,295 & 16 & $72,7 \%$ & 6 & $27,3 \%$ & 098 & 12 & $54,5 \%$ & 10 & $45,5 \%$ & 1,000 \\
\hline Çalıșma pozisyonu & Evet & 33 & $75,0 \%$ & 11 & $25,0 \%$ & 0609 & 23 & $52,3 \%$ & 21 & $47,7 \%$ & 1000 & 25 & $56,8 \%$ & 19 & $43,2 \%$ & 0.90 & 24 & $54,5 \%$ & 20 & $45,5 \%$ & 0854 \\
\hline eğitimi aldmı $\mathrm{ml}$ ? & Hayr & 32 & $82,1 \%$ & 7 & $17,9 \%$ & 0,609 & 20 & $51,3 \%$ & 19 & $48,7 \%$ & 1,000 & 21 & $53,8 \%$ & 18 & $46,2 \%$ & 0,960 & 23 & $59,0 \%$ & 16 & $41,0 \%$ & 0,854 \\
\hline & Ara sira & 33 & $80,5 \%$ & 8 & $19,5 \%$ & & 23 & $56,1 \%$ & 18 & $43,9 \%$ & & 22 & $53,7 \%$ & 19 & $46,3 \%$ & & 24 & $58,5 \%$ & 17 & $41,5 \%$ & \\
\hline Ișinizde oturarak & Siklikla/genellikle & 24 & $80,0 \%$ & 6 & $20,0 \%$ & 0,570 & 16 & $53,3 \%$ & 14 & $46,7 \%$ & 0,369 & 17 & $56,7 \%$ & 13 & $43,3 \%$ & 0,946 & 19 & $63,3 \%$ & 11 & $36,7 \%$ & 0,196 \\
\hline & Sürekli & 8 & $66,7 \%$ & 4 & $33,3 \%$ & & 4 & $33,3 \%$ & 8 & $66,7 \%$ & & 7 & $58,3 \%$ & 5 & $41,7 \%$ & & 4 & $33,3 \%$ & 8 & $66,7 \%$ & \\
\hline & Ara sra & 28 & $82,4 \%$ & 6 & $17,6 \%$ & & 19 & $55,9 \%$ & 15 & $44,1 \%$ & & 18 & $52,9 \%$ & 16 & $47,1 \%$ & & 20 & $58,8 \%$ & 14 & $41,2 \%$ & \\
\hline Ișinizde ayakta çalıșır & Siklikla/genellikle & 17 & $70,8 \%$ & 7 & $29,2 \%$ & 0,560 & 10 & $41,7 \%$ & 14 & $58,3 \%$ & 0,499 & 18 & $75,0 \%$ & 6 & $25,0 \%$ & 0,045 & 11 & $45,8 \%$ & 13 & $54,2 \%$ & 0,415 \\
\hline & Sürekli & 20 & $80,0 \%$ & 5 & $20,0 \%$ & & 14 & $56,0 \%$ & 11 & $44,0 \%$ & & 15 & $60,0 \%$ & 10 & $40,0 \%$ & & 16 & $64,0 \%$ & 9 & $36,0 \%$ & \\
\hline & Ara sira & 14 & $63,6 \%$ & 8 & $36,4 \%$ & & 9 & $40,9 \%$ & 13 & $59,1 \%$ & & 12 & $54,5 \%$ & 10 & $45,5 \%$ & & 11 & $50,0 \%$ & 11 & $50,0 \%$ & \\
\hline izde eğilerek çalhṣır & Siklikla/genellikle & 21 & $75,0 \%$ & 7 & $25,0 \%$ & 0,048 & 12 & $42,9 \%$ & 16 & $57,1 \%$ & 0,088 & 17 & $60,7 \%$ & 11 & $39,3 \%$ & 0,768 & 15 & $53,6 \%$ & 13 & $46,4 \%$ & 0,560 \\
\hline & Sürekli & 30 & $90,9 \%$ & 3 & $9,1 \%$ & & 22 & $66,7 \%$ & 11 & $33,3 \%$ & & 17 & $51,5 \%$ & 16 & $48,5 \%$ & & 21 & $63,6 \%$ & 12 & $36,4 \%$ & \\
\hline
\end{tabular}


Çalışmaya katılan diş hekimlerinin \%94'nün vücudunun herhangi bir bölgesinde ağrı bulunduğu, \%79,5'inin son 12 ay içerisinde ağrı olan vücut bölgesinden sorun yaşadığı, $\% 69,9$ 'unun son bir ay içerisinde ağrısının olduğu ve \%48,2'sinde anket doldurulan gün ağriyan bölgesinde sorun (ac1, ağrı, rahatsızlık hissi) olduğu görülmektedir. En fazla ağr1 şikayeti olan vücut bölgelerinin sırasıyla \%78,3'ünün boyun, \%56,6'sının bel, \%55,4'ünün sırt olduğu saptanmıştır.

\section{Tartışma}

ABD'de 95 diş hijyenistinde yapılan bir çalışmada son 12 ay içindeki kas-iskelet sistemi rahatsızlığı sıklığ \%93,0 bulunmuştur (16). Kandemir ve arkadaşlarının diş hekimlerinde yaptığı bir çalışmada son 12 ay içinde diş hekimlerinin \%82'sinin, son bir haftada \%50'sinin kasiskelet sistemi ağrısı yaşadıkları saptanmıştır (7). Doğan'ın Ankara'daki ADSM'lerde yaptığı çalışmada çalışan diş hekimlerinin herhangi bir zamanda, son 12 ayda, son bir ayda ve anketin yapıldığ 1 gün, kas-iskelet sistemine ilişkin ağrılarının sıklığı sırasıyla \%97,7, \%94,4, \%89,0, \%64,3 olduğu saptanmıştır (11).

Nokhostin ve Zafarmand'ın yaptıkları çalışmada da benzer şekilde diş hekimlerinin \% 67.5'ünün fiziksel sorunları olduğunu belirtilmiştir (17). Gopinadh ve arkadaşlarının 2013 yılında yaptıkları başka bir çalışmada da diş hekimlerinin 289 $(\% 73,9)$ 'unun kas-iskelet sistemi ağrısını yaşadıkları, bunların 119 'unda $(\%$ 30,4) vücutlarının birden fazla bölümünde ağrı olduğunu belirtmişlerdir (18).

$\mathrm{Bu}$ çalışmanın sonuçları daha önce yapılan diğer çalışma verileri benzerlikler göstermektedir (7, 15-18). Hayes ve arkadaşlarının 2009 yılında diş hekimliği profesyonellerinde (diş hekimi, diş hijyenisti ve diş hekimliği öğrencileri) kasiskelet sistemi semptomlarının yaygınlığı ve bu problemle ilgili potansiyel risk faktörlerinin belirlenmesine ilişkin literatür taramasında genel kas-iskelet sistemi ağrıs1 prevalansının \% 64- \% 93 arasında olduğu belirtilmiştir (19).

Yapılan analizlerin sonucu en fazla sorun olarak algılanan vücut bölgesi sırası ile boyun, bel ve sırt bölgeleridir. Kandemir ve Karataş diş hekimlerinde kas-iskelet sistemi yakınma bölgesi olarak en çok sırt (\% 79) ve bel (\% 79) bölgesi ağrısı olduğunu saptamıştır (7). Akesson ve arkadaşlarının 1999'da yaptığı çalışmada da kas-iskelet sistemi rahatsızlıklarının en çok boyun ve omuz bölgesinde görüldüğü bildirilmiştir (20). Nokhostin ve Zafarmand'ın yaptığı çalışmada ise diş hekimlerinin boyunlarında (\% 51.87), bileklerinde ( $\%$ 92.96), bellerinde (\% 11.11) ve omuzlarında (\% 7.40) kasiskelet sistemi yakınmalarının gözlendiği bildirilmiştir (17). Avusturalya'nın Queensland eyaletinde diş hekimlerinde yapılan başka bir çalışmada da diş hekimlerinin önceki 12 ay süresince en sık görülen kas-iskelet sistemi bozukluklarının boyun $(\% 57,5)$, sirt $(\% 53,7)$ ve omuz $(\% 53,3)$ bölgesinde olduğu belirtilmiştir (21). Diğer bir çalışmada ise, diş hekimlerinin en sık ağrıdan yakındığı vücut bölgelerinin sırasıyla boyun, sırt ve omuzları olduğunu bildirmişlerdir (18).

Hayes ve arkadaşları tarafından yapılan literatür taramasında diş hekimlerinde ağrı için en yaygın bölgelerin sırasıyla sırt
(\% 36.3-60.1) ve boyun (\% 19.8-85), diş hijyenistleri için ise en yaygın bölgelerin el ve bilek bölgeleri (\% 60-69.5) olduğu saptanmıştır (19).

Çalışmada kas-iskelet sistemi rahatsızlığı ile cinsiyet arasında istatistiksel olarak anlamlı bir fark bulunmuştur. Araştırmada kadın hekimlerin kas-iskelet sistemi yakınmalarının erkek diş hekimlerine göre daha sık olduğu belirlenmiştir. Kadın diş hekimlerinin \%87,8'i son bir ay içinde kas-iskelet sistemi rahatsızlığı yaşarken bu oran erkek diş hekimlerinde \%52,4'tür. Benzer şekilde Kandemir ve Karataş'ın, 2001 yılında yaptığı çalışmada kas-iskelet sistemi yakınmalarının daha çok bayanlarda, ayakta ve günde 11 saatten fazla çalışan diş hekimlerinde görüldüğü bildirilmiştir (7). Diğer bazı çalışmalarda ise kas-iskelet sistemi rahatsızlığına cinsiyetin etkisi üzerine farklı sonuçlar bildirilmiştir.

Al-Shehri ve Al-Zoughool son 12 ay içinde kas-iskelet sistemi rahatsızlığı sıklığının kadın diş hekimlerinde \%81,1, erkek diş hekimlerinde $\% 73,5$ olduğunu fakat bu farkın istatistiksel olarak anlamlı olmadığını bildirmişlerdir (22). Doğan'ın alıntı yaptığı, Chowanidisai ve arkadaşları son 12 ay içinde kas-iskelet sistemi rahatsızlığı sıklığının kadın diş hekimlerinde $\% 81,1$, erkek diş hekimlerinde $\% 73,5$ olduğunu ancak bu farkın istatistiksel olarak anlamlı bulmadıklarını belirtmişlerdir $(11,23)$.

Meslekte çalışma süresi ile ilgili yapılan analizler, çalışma süresi 5 yıl ve daha az olanların son bir ay içerisinde ağrı, ac1, rahatsızlık hissi gibi sorunlar yaşamadığını, çalışma süresi 16 yıl ve daha fazla olanların son bir ay içerisinde ağrı, acı, rahatsızlık hissi gibi sorunlar yaşadığını göstermiştir. Ayrıca çalışma süresi ile son bir ay içerisinde herhangi bir zamanda ağrı, acı, rahatsızlık hissi gibi kas-iskelet sistemi sorunları arasında istatistiksel olarak anlamlı ilişki bulunmuştur $(\mathrm{p}<0,05)$.

Meslekte çalışma süresi ile kas-iskelet sistemi rahatsızlığ arasındaki ilişkiyi araştıran çalışmalar arasında farklı sonuçlar bulunmuştur. Yaptığımız çalışma sonuçlarının aksine Doğan'ın alıntı yaptığı Chowanidisai ve arkadaşlarının Tayland'da diş hekimlerinde yaptığı bir çalışmada, meslekteki deneyim süresi ile kas-iskelet sistemi ağrısının ters ilişkili olduğu bildirilmiştir $(11,23)$. Yine bu çalışma sonuçlarının aksine Avusturalya'nın Queensland eyaletinde yapılan başka bir çalışmada da daha genç ve daha az tecrübeli diş hekimlerinde sıklıkla bel, boyun ve boyun ağrısı saptanmıştır (21).

Yapılan analizlerde diş hekimlerinin yaşları ve kas-iskelet sistemi ağrıları arasında anlamlı bir ilişki gösterilememiştir. Ancak çalışma sonuçlarımızdan farklı olarak Nokhostin ve Zafarmand tarafından yapılan çalışmada diş hekimlerinin yaş, vücut kütle indeksi, baktıkları günlük hasta sayısı ve fiziksel aktivite arasında doğrudan bir ilişki olduğu belirtilmiştir (17). Yine Gopinadh ve arkadaşları erkek diş hekimlerinin daha fazla ağrıdan yakındığını, ağrılarının yaşla birlikte arttığını bildirmişlerdir. Çalışma saati 8 ve fazla olan diş hekimlerinin kas-iskelet sistemi yakınmalarının daha az süre çalışanlara göre daha fazla olduğunu belirlemişlerdir (18).

$\mathrm{Bu}$ çalışmaya katılan diş hekimleri arasında işini sürekli 
eğilerek yapanların \%87,9'unda, ara sıra eğilerek yapanların \%54,5'inde son bir ay içinde ağrı oluştuğu ve sonuçların istatistiksel bakımdan anlamlı olduğu bulunmuştur. Bu çalışmada da görüldüğü gibi katılımcıların çalışma pozisyonunu kas-iskelet sistemini zorlamadan ayarlamalarının oluşabilecek ağrı ve şikayetleri önlemede anlamlı bir etkisi vardır diyebiliriz.

$\mathrm{Bu}$ sonuçlar, Finsen ve arkadaşlarının çalışma sonuçları ile uyumludur. Finsen ve arkadaşlarının Danimarka'da diş hekimlerinde yaptığı çalışmada çalışma süresince uzun zaman eğilerek boyun kaslarını germek, uzun süreli sabit çalışma şeklinin boyun ve omuz bölgesinde yüksek statik kas yüküne bağlı kas-iskelet sistemi rahatsıllılarına neden olabileceği gösterilmiştir $(11,24)$.

Benzer şekilde Kierklo ve arkadaşlarının yaptığı bir çalışmada diş hekimlerinin kas-iskelet sistemi problemleri ile çalışma pozisyonları (ayakta çalışan) ve dinleme molası kullanmamaları arasında anlamlı ilişki bulunmuştur. Diş hekimlerinin çalışma ortamında sınırlı ergonomik duruşun kas-iskelet sistemi problemlerine neden olduğu ve prevalansının çok yükssek olduğu belirlenmiştir (25).

Suudi Arabistan'daki diş hekimleri arasında işle ilgili kasiskelet sistemi yakınmalarının yaş, cinsiyet, işin özellikleri, çalışma ortamı, hastalarla temas saatleri ile ilişkili olduğu saptanmıştır (26).

\section{Sonuç}

Çalışmamızda araştırmaya katılan diş hekimlerinin \%79,5'inde son 12 ay içinde çalışma şartlarından kaynaklanan kas-iskelet sistemi problemleri olduğu görülmüştür. Aynı pozisyonda uzun bir süre çalışmak zorunda kalan diş hekimlerinin mesleklerini icra ederken gelişen kas-iskelet sistemi sorunlarını azaltmak için koruyucu bir takım önlemleri (oturarak çalışılması, çalışmaya sık sık ara verilmesi, düzenli egzersiz yapılması vs) uygulayabilmelerinin faydalı olacağ düşünülmektedir.

\section{Kaynakça}

1. Buğdaycı R, Kurt AÖ, Tezcan H, Şaşmaz T, Kuruloğlu N, Yüceer NT, Küçük B. İçel İlinde Görev Yapan Hekimlerde Ruhsal Tükenmişlik Durumu ve Etkileyen Faktörler. Sağlık Çalışanlarının Sağlığı 2. Ulusal Kongresi. Ankara. Genel-İş Matbaas1, 2001, p: 141.

2. Unal D, Aycan N. Manisa MAY Tekstil San. A.S.'de calisan iscilerin isyeri saglik birimi'ne basvuru nedenlerinin ve sosyodemografik ozelliklerinin incelenmesi. Hemsirelik Forumu Dergisi. 2003;6(1):49-57.

3. Warming S, Precht DH, Suadicani P, Ebbehoj NE. Musculoskeletal complaint anong nurses related to patient handling tasks and psychosocial factors-Based on logbook registrations. Appl Ergon 2009; 40: 569-576.

4. Tezel A. Musculoskeletal complaints among a group of Turkish nurses. Int j Neurosci 2005; 115: 871-880.

5. Harcombe H, McBride D, Derrett S, Gray A. Physical and psychosocial risk factors for musculoskeletal disorders in
New Zealand nurses, postal workers and office workers. Inj Prev 2010; 16: 96-100.

6. Diraçoğlu D. Sağlık personelinde kas-iskelet sistemi ağrıları. Türkiye Klinikleri J Med Sci 2006; 26:132-139.

7. Kandemir S, Karataş S. Mesleğini sürdüren diş hekimlerinin mesleğe bağlı sağlık şikayetlerinin belirlenmesi. Cumhuriyet Üniversitesi Diş Hekimliği Fakültesi Dergisi 2001; 4: 41-46.

8. Şenel B. Diş hekimleri için risk taşıyan hastalıklar ve diş hekimlerinin mesleki rahatsızlıkları, Gülhane Tıp Dergisi 2007;49:204-212.

9. Landeras S, Felsenfeld AL. Ergonomics and dental office. An overview and consideration of regulating influences. J Calif Dent Assoc 2002; 30: 137-8.

10. Valachi B, Valachi K. Mechanisms leading to musculoskeletal disorders in dentistry. J Am Dent Assoc 2003; 134: 1344-50.

11. Doğan, A. Ankara'da Bulunan Ağı Ve Diş Sağlı̆̆1 Merkezlerinde Çalışan Diş Hekimlerinde Kas İskelet Sistemi Yakınmaları Ve Etkileyen Faktörler, Uzmanlık tezi, Hacettepe Üniversitesi Tıp Fakültesi Halk Sağlığı Anabilim Dalı. 2011.

12. Groeneveld, RA and Meeden, G. Measuring Skewness and Kurtosis. The Statistician, 1984; 33: 391-399.

13. Moors, JJA. The Meaning of Kurtosis: Darlington Reexamined. The American Statistician. 1986; 40: 283-284.

14. Hopkins, KD and Weeks, DL. Tests for Normality and Measures of Skewness and Kurtosis: Their Place in Research Reporting. Educational and Psychological Measurement. 1990; 50: 717-729.

15. De Carlo, LT. On the Meaning and Use of Kurtosis. Psychological Methods, 1997; 2: 292-307.

16. Anton D, Rosecrance J, Merlino L, Cook T. Prevalence of musculoskeletal symptoms and carpal tunnel syndrome among dental hygienists. Am J Ind Med, 2002;42(3):248-57.

17. Nokhostin MR, Zafarmand AH. "Musculoskeletal problem": Its prevalence among Iranian dentists. J Int Soc Prev Community Dent. 2016;6 (1). 41-6.

18. Gopinadh A, Kolli Naga Neelima Devi KNND, Chiramana S, Manne P, Sampath A, Babu MS. Ergonomics and Musculoskeletal Disorder: As an Occupational Hazard in Dentistry. The Journal of Contemporary Dental Practice. 2013;14(2):299-303.

19. Hayes M, Cockrell D, Smith DR. A systematic review of musculoskeletal disorders among dental professionals. Int $\mathrm{J}$ Dent Hyg. 2009;7(3):159-65.

20. Akesson I, Johnsson B, Rylander L, Moritz U, Skerfving S. Musculoskeletal disorders among female dental personnelclinical examination and a 5-year follow up study of symptoms. Int Arch Occup Environ Health.1999;72(6):395-403.

21. Leggat PA, Smith DR. Musculoskeletal disorders selfreported by dentists in Queensland, Australia. Aust Dent J, 2006; 51(4): 324-7.

22. Al-Shehri Z. and Al-Zoughool M. Self-reported musculoskeletal symptoms among dentists in Saudi Arabia. 
Ind Health; 2017;55(4): 338-344.

23. Chowanidisai S, Leggat PA, Kukiattrakoon B, Yapong B, Kedrajarune U. Occupational health problems of dentists in Southern Thailand. Int Dent J 2000; 50:36-40.

24. Finsen L, Christensen H, Bakke M. Musculoskeletal disorders among dentists and variation in dental work. Appl Ergon, 1998; 29(2): 119-25.
25. Kierklo A, Kobus A, Jaworska M, Botuliński B. Work-related musculoskeletal disorders among dentists - a questionnaire survey. Ann Agric Environ Med. 2011; 18(1):79-84.

26. Alghadir, A, Zafar, H, \& Iqbal, ZA. Work-related musculoskeletal disorders among dental professionals in Saudi Arabia. Journal of Physical Therapy Science, 2015;27(4):1107-1112. 